\title{
Pengaruh Tekanan Ketaatan Pada Audit Judgment Dengan Religiusitas Sebagai Variabel Pemoderasi
}

\author{
Luh Putu Lusi Setyandarini Surya ${ }^{1}$ \\ Fakultas Ekonomi dan Bisnis \\ Universitas Warmadewa, Indonesia \\ Email: lusisurya160@gmail.com
}

\author{
Cok Istri Ratna Sari Dewi² \\ Fakultas Ekonomi dan Bisnis \\ Universitas Warmadewa, Indonesia
}

\begin{abstract}
ABSTRAK
Tekanan ketaatan berpengaruh pada audit judgment namun tidak senantiasa linier karena adanya faktor kontigensi, salah satunya yaitu religiusitas. Tujuan dari penelitian ini adalah untuk memperoleh bukti empiris mengenai pengaruh tekanan ketaatan pada audit judgment, serta kemampuan religiusitas dalam memoderasi pengaruh tekanan ketaatan pada audit judgment. Sampel penelitian ini diambil dengan metode sampel jenuh. Pengumpulan data dilakukan dengan menggunakan kuesioner yang diberikan kepada 65 auditor di KAP se-Provinsi Bali sebagai responden. Teknik analisis data yang digunakan adalah regresi linier sederhana dan Moderated Regression Analysis (MRA). Hasil penelitian menunjukkan bahwa tekanan ketaatan berpegaruh negatf pada audit judgment dan religiusitas mampu memoderasi pengaruh tekanan ketaatan pada audit judgment.
\end{abstract}

Kata Kunci : Tekanan Ketaatan; Audit Judgment; Religiusitas.

\section{The Effect of Obedience Pressure on Audit Judgment With Religiosity As Moderating Variable}

\section{ABSTRACT}

Obedience pressure is one of the factors that can influence audit judgment. This compliance pressure arises due to the expectation gap that occurs between the entity examined and the auditor that has caused conflict for the auditor. Previous research suggest that obedience pressure is not consistently affecting audit judgment. The aim of this research is to gather empirical evidence of the effect of obedience pressure on audit judgment with religiosity as moderating variables. The sample for this research is taken with census sampling method. The data were collected by using questionnaire, given to 65 auditors who work at Public Accountant Firm all over the Province of Bali. The data were analysed using Simple Linier Regression and Moderated Regression Analysis (MRA). The result showed that obedience pressure is negatively affecting audit judgment and religiosity is able to moderate the effect of obedience pressure on audit judgment.

Keywords : $\quad$ Obedience Pressure; Audit Judgment; Religiosity.

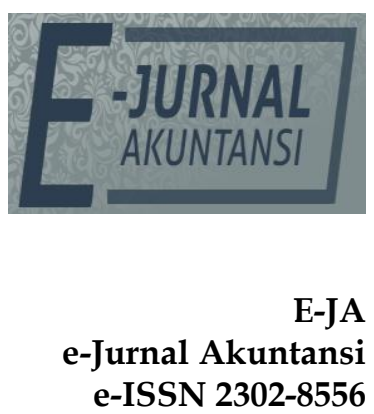

Vol. 29 No. 2

Denpasar, November 2019

Hal. 673-682

Artikel masuk: 14 Oktober 2019

Tanggal diterima: 11 November 2019 


\section{PENDAHULUAN}

Salah satu cara untuk mengukur kualitas hasil pekerjaan auditor adalah melalui kualitas keputusan-keputusan yang diambil (Wibowo \& Rossieta, 2009). Terdapat dua pendekatan untuk mengevaluasi sebuah keputusan secara umum, yaitu outcome oriented dan process oriented (Bedard \& Michelene, 1993). Judgment sebagai proses kongnitif yang merupakan perilaku pemilihan keputusan. Dalam membuat suatu judgment, auditor akan mengumpulkan berbagai bukti relevan dalam waktu yang berbeda dan kemudian mengintegrasikan informasi dari bukti-bukti tersebut (Magdalena, Sofiani, \& Tjondro, 2014). Judgment merupakan suatu proses yang terus menerus dalam perolehan informasi (termasuk umpan balik dari tindakan sebelumnya), pilihan untuk bertindak atau tidak bertindak, penerimaan informasi lebih lanjut. Proses judgment tergantung pada kedatangan informasi sebagai suatu proses pengembangan. Kedatangan informasi tidak hanya mempengaruhi pilihan, tapi juga mempengaruhi cara pilihan tersebut dibuat (Hogarth \& Einhorn, 1992).

Tekanan dari berbagai pihak yang berkepentikangan diperkirakan dapat mempengaruhi pengambilan keputusan (Hartanto \& Wjaya, 2001). Akuntan secara terus menerus mengalami dilema etika yang melibatkan pilihan antara nilai-nilai yang bertentangan, sehingga klien bisa saja mempengaruhi proses pemeriksaan yang dilakukan auditor yakni dengan menekan auditor untuk mengambil tindakan yang melanggar standar pemeriksaan (Jamilah, Fanani, \& Chandrarin, 2007). Tekanan klien adalah suatu hal yang sudah menjadi resiko dari profesi akuntan publik, maka pertimbangan profesional seorang auditor yang berlandaskan pada nilai dan keyakinan individu serta kesadaran moral memainkan peranan penting dalam setiap keputusan auditor dalam menghadapi tekanan klien.

Penelitian sebelumnya yang dilakukan oleh (Jamilah et al., 2007), (Wijayatri, 2010), (Praditaningrum, 2012) dan (Astriningrum, 2012) memberikan bukti bahwa tekanan ketaatan dapat memengaruhi auditor dalam membuat suatu judgment. Namun terdapat beberapa penelitian yang menyatakan hasil yang berbeda seperti penelitian yang dilakukan oleh (Idris, 2012) dan (Puspitasari, 2014) yang menyatakan bahwa tekanan ketaatan tidak berpengaruh terhadap audit judgment. Hasil-hasil penelitian terdahulu yang tidak konsisten diduga karena ada faktor lain yang mempengaruhi hubungan antara variabel bebas dengan variabel terikat.

Theory of Reasoned Action (TRA) merupakan niat seseorang untuk melakukan suatu perilaku dipengaruhi oleh dua penentu dasar yaitu sikap dan hal-hal yang berhubungan dengan pengaruh sosial yaitu norma subyektif (Ajzen, 1980). TRA kemudian dikembangkan lebih lanjut menjadi Theory of Planned Behavior (TPB) dimana teori ini menjelaskan persepsi individu terhadap kontrol yang mereka miliki terhadap perilaku mereka. Religiusitas didefinisikan sebagai suatu sistem yang terintegrasi dan keyakinan (belief), gaya hidup memberikan makna dalam kehidupan manusia dan mengarahkan manusia pada nilai-nilai suci atau nilai-nilai tertinggi (Nazaruddin, 2011). Religiusitas mempengaruhi standar moral seseorang (Barnett, Bass, \& Brown, 1996). Tingkat religiusitas seorang auditor mempengaruhi kecenderungan auditor untuk tidak melakukan perilaku disfungsional audit (Evanauli \& Nazaruddin, 2013). Seseorang dengan 
tingkat religiusitas yang tinggi akan menghidari hal-hal menyimpang dari agama seperti melakukan kecurangan dan pemanipulasian (Clary \& Snyder, 1991). Religiusitas membantu para auditor untuk meningkatkan kualitas judgmentnya

Penelitian ini dilakukan untuk meneliti pengaruh tekanan ketaatan pada audit judgment dengan variabel religiusitas sebagai pemoderasi. Hasil penelitian ini diharapkan dapat memberikan hasil baik mendukung ataupun tidak mendukung teori, serta untuk menegaskan hasil penelitian-penelitian yang telah dilakukan terdahulu. Selain itu, berdasarkan hasil penelitian diharapkan auditor independen mempertimbangkan aspek religiusitas dalam sistem pengendalian mutu KAP guna meningkatkan perilaku etis auditor.

Kemungkinan belum adanya kesatuan hasil penelitian tergantung faktorfaktor tertentu atau lebih dikenal dengan istilah faktor kontinjensi (Govindarajan, 1986). Agar dapat merekonsiliasi hasil yang saling bertentangan diperlukan pendekatan kontinjensi untuk mengidentifikasi variabel lain yang bertindak sebagai pemoderasi ataupun pemediasi dalam model riset (Murray, 1990).

Theory of Reasoned Action (TRA) yang dicetuskan oleh (Ajzen, 1980) menyatakan bahwa niat seseorang untuk melakukan suatu perilaku dipengaruhi oleh dua penentu dasar yaitu sikap dan hal-hal yang berhubungan dengan pengaruh sosial yaitu norma subyektif. TRA kemudian dikembangkan lebih lanjut menjadi Theory of Planned Behavior (TPB) dimana teori ini menjelaskan persepsi individu terhadap kontrol yang mereka miliki terhadap perilaku mereka. Salah satu variabel yang termasuk kedalam model teoritik TPB yaitu faktor latar belakang (background factors), yang pada dasarnya adalah sifat yang hadir dalam diri seseorang yang berpengaruh terhadap sikap dan norma subjektif seseorang.

Tekanan ketaatan mengarah kepada tekanan yang didapatkan dari atasan dan juga tekanan yang didapatkan dari entitas yang diperiksa. Perbedaan harapan antara entitas yang diperiksa dengan auditor merupakan hal yang menyebabkan tekanan ketaatan terjadi. Pada saat perbedaan harapan itu terjadi, maka entitas yang diperiksa akan berusaha untuk menekan auditor untuk menyamakan harapannya yang memicu timbulnya tekanan dari atasan. Tekanan dari atasan ini berupa perintah untuk menyimpang dari standar yang telah ditentukan dan menyebabkan dilema etika pada auditor.

$\mathrm{H}_{1}$ :Tekanan ketaatan berpengaruh negatif pada audit judgment.

Religiusitas mempengaruhi standar moral seseorang (Barnett et al., 1996). Religiusitas memberikan kontribusi terhadap idealisme seseorang (Hood, Greildan, \& Bromley, 2003). Tingkat religiusitas seorang auditor mempengaruhi kecenderungan auditor untuk tidak melakukan perilaku disfungsional audit (Evanauli \& Nazaruddin, 2013). Seseorang dengan tingkat religiusitas yang tinggi akan menghidari hal-hal menyimpang dari agama seperti melakukan kecurangan dan pemanipulasian (Clary \& Snyder, 1991). Religiusitas membantu para auditor untuk meningkatkan kualitas judgmentnya (Alteer \& Taher, 2015).

$\mathrm{H}_{2}$ :Religiusitas mampu memperlemah pengaruh tekanan ketaatan pada audit judgment. 


\section{METODE PENELITIAN}

Lokasi penelitian dilakukan pada KAP yang terdapat di Provinsi Bali. Obyek penelitian pada penelitian ini adalah seluruh auditor independen pada KAP yang terdapat di Provinsi Bali. Sumber data pada penelitian ini adalah data primer. Data Primer adalah data yang diperoleh dari sumber pertama (Saifudin, 2001). Data primer dalam penelitian ini adalah jawaban responden atas kuesioner. Populasi pada penelitian ini adalah seluruh auditor di KAP seProvinsi Bali yang masih aktif beroperasi sesuai dengan kondisi di lapangan, dengan kriteria telah memiliki kemampuan teknis yang cukup, dengan tingkat Pendidikan minimal D3. Teknik penentuan sampel menggunakan metode sampel jenuh.

Variabel terikat dalam penelitian ini adalah audit judgment. Auditor judgment adalah kebijakan auditor dalam menentukan pendapat mengenai hasil auditnya yang mengacu pada pembentukan suatu gagasan, pendapat atau perkiraan suatu obyek, peristiwa, status dan jenis peristiwa lain. Audit judgment diukur dengan menggunakan rancangan kuesioner yang diadopsi dari penelitian Puspitasari (Saifudin, 2001) dengan menggunakan tiga indikator yaitu tingkat materialitas, tingkat resiko audit dan kelangsungan hidup suatu entitas.

Variabel bebas dalam penelitian ini adalah tekanan ketaatan. Tekanan ketaatan adalah tekanan yang diterima oleh auditor dalam menghadapi atasan dan klien untuk melakukan tindakan menyimpang dari standar etika. Tekanan ketaatan diukur dengan menggunakan rancangan kuesioner yang diadopsi dari penelitian Jamilah (Jamilah et al., 2007).

Variabel pemoderasi pada penelitian ini adalah religiusitas. Variabel Pemoderasi, yaitu variabel yang dapat memperkuat atau memperlemah hubungan antara variabel bebas dengan variabel terikat (Sugiyono, 2013). Religiusitas adalah keyakinan (belief), gaya hidup spiritual, aktivitas ritual yang menjunjung nilai-nilai suci berdasarkan keyakinan yang dimiliki/dianut oleh auditor. Pada penelitian ini tingkat religiusitas auditor diukur dengan menggunakan kuesioner yang dikembangkan dari Religious Commitment Inventory (RCI-10) yang dicetuskan oleh Worthington (Worthington et al., 2003) yang diukur dengan Skala Likert lima poin.

Metode pengumpulan data yang digunakan adalah metode survei dengan Teknik kuesioner. Kuesioner yang digunakan dalam penelitian ini yaitu kuesioner yang diadopsi dari kuesioner pada penelitian-penelitian sebelumnya yaitu audit judgment, tekanan ketaatan dan religiusitas.

Analisis pertama diawali dengan melakukan uji validitas dan reliabilitas instrumen. Selanjutnya dilakukan uji asumsi klasik yang terdiri dari: uji normalitas, uji multikolinieritas, dan uji heterokedastisitas. Dalam penelitian ini, hipotesis pertama diuji dengan analisis regresi linier sederhana, dan hipotesis kedua diuji dengan Moderated Regression Analysis (MRA). 


\section{HASIL DAN PEMBAHASAN}

Berdasarka jumlah kuesioner yang disebarkan kepada responden yaitu sebanyak 65 kuesioner, 49 kuesioner kembali dan layak dianalisis dengan tingkat pengembalian kuesioner sebesar $75 \%$. Hasil statistic deskriptif dari masingmasing variabel disajikan pada tabel 1 .

\section{Tabel 1. Hasil Statistik Deskriptif}

\begin{tabular}{lccccc}
\hline \multicolumn{1}{c}{ Variabel } & N & Minimum & Maksimum & Mean & $\begin{array}{c}\text { Std. } \\
\text { Dviasi }\end{array}$ \\
\hline Tekanan Ketaatan (X1) & 49 & 9,00 & 33,46 & 16,70 & 8,06 \\
Religiusitas (X2) & 49 & 29,32 & 83,58 & 64,05 & 16,43 \\
Audit Judgment (Y) & 49 & 6,00 & 22,36 & 17,14 & 5,49 \\
\hline
\end{tabular}

Sumber: Data Penelitian 2019

Berdasarkan Tabel 1 dapat dilihat bahwa Variabel Tekanan Ketaatan (X1) memiliki nilai minimum ssebesar 9,00, nilai maksimum sebesar 33,46, mean sebesar 16,70, dan standar deviasi sebesar 8,06 menunjukkan bahwa tekanan ketaatan yang dihadapi responden tergolong rendah.

Variabel Religiusitas (X2) memiliki nilai minimum sebesar 29,32, nilai maksimum sebesar 83,58, mean sebesar 64,05, dan standar deviasi sebesar 16,43. Nilai mean sebesar 64,05 menunjukkan bahwa responden tergolong cukup religius.

Variabel Audit Judgment (Y) memiliki nilai minimum sebesar 6,00, nilai maksimum sebesar 22,36, mean sebesar 17,14, dan standar deviasi sebesar 5,49. Nilai mean sebesar 17,14 menunjukkan bahwa kualitas audit judgment responden tergolong tinggi.

Hasil uji validitas instrumen menunjukkan bahwa nilai koefisien korelasi terhadap ke tiga puluh lima item pada kuesioner telah menunjukkan koefisien korelasi lebih besar dari 0,30, maka dari itu seluruh item kuesioner dinyatakan valid. Berdasarkan uji reliabilitas yang dilakukan menunjukkan bahwa nilai cronbach alpha untuk variabel audit judgment sebesar 0,967, variabel tekanan ketaatan sebesar 0,973, dan variabel religiusitas sebesar 0,972 telah lebih besar dari 0,60 sehingga pernyataan pada kuesioner yang digunakan telah reliabel.

Uji Normalitas dilakukan untuk menguji apakah model regresi, variabel terikat dan variabel bebas telah berdistribusi normal (Ghozali, 2004). Uji normalitas dilakukan dengan uji analisis statistik Kolmogorov-Smirnov. Hasil uji normalitas dapat dilihat dari nilai signifikansinya, jika nilai signifikansi di atas a maka distribusi data adalah normal. Hasi uji normalitas pada penelitian ini dapat dilihat pada Tabel 2.

Tabel 2. Uji Normalitas

\begin{tabular}{lcccc}
\hline & $\mathrm{N}$ & & $\begin{array}{c}\text { Komlogorov- } \\
\text { Smirnov }\end{array}$ & $\begin{array}{c}\text { Asymp.sig (2- } \\
\text { tailed) }\end{array}$ \\
\hline Unstandarized & \multirow{2}{*}{49} & Uji Regresi Sederhana & 0,120 & 0,075 \\
Residual & Regresi Moderasi & 0,125 & 0,054 \\
\hline
\end{tabular}

Sumber: Data Penelitian, 2019

Hasil uji normalitas Kolmogorov-Smirnov menunjukkan bahwa berdasarkan Sig. (2-tailed), dapat dilihat bahwa Asym.Sig (2-tailed) pada pengujian regresi sederhana $(0,075)$ dan pengujian regresi moderasi $(0,054)$ lebih besar dari 
level of significant $(0,050)$, sehingga dapat disimpulkan bahwa variabel audit judgment, tekanan ketaatan dan religiusitas telah berdistribusi dengan normal.

Uji multikolinieritas melihat nilai tolerance atau Variance Inflation Factor (VIF). Jika tolerance lebih dari 10\% atau VIF kurang dari 10 maka dikatakan tidak ada multikolinieritas. Hasil pengujian dapat dilihat pada Tabel 3.

Tabel 3. Uji Multikolinearitas

\begin{tabular}{llcc}
\hline & Variabel & Tolerance & VIF \\
\hline \multirow{2}{*}{ Regresi Moderasi } & Tekanan Ketaatan (X1) & 0,498 & 2,007 \\
& Religiusitas (X2) & 0,508 & 1,969 \\
\hline
\end{tabular}

Sumber: Data Penelitian, 2019

Berdasarkan Tabel 3 dapat dilihat bahwa nilai tolerance masing-masing variabel memiliki VIF di bawah 10 dan nilai tolerance di atas 0,10 sehingga dapat disimpulkan bahwa tidak terjadi hubungan multikolinieritas antar variabel bebas.

Pengujian heteroskedastisitas dilakukan untuk melihat apakah dalam model regresi terjadi ketidaksamaan variance dari residual satu pengamatan ke pengamatan lain. Pengujian heteroskedastisitas dilakukan dengan uji Glejser dengan melihat tingkat signifikansi. Jika tingkat signifikansi berada di atas 0,050 maka model regresi ini bebas dari masalah heteroskedastisitas. Hasil uji ini dapat dilihat pada Tabel 4 .

Tabel 4. Hasil Uji Heteroskedastisitas

\begin{tabular}{lll}
\hline & Variabel & Sig \\
\hline Uji Regresi Sederhana & Tekanan Ketaatan (X1) & 0,137 \\
\multirow{2}{*}{ Regresi Moderasi I } & Tekanan Ketaatan (X1) & 0,731 \\
& Religiusitas (X2) & 0,100 \\
\hline
\end{tabular}

Sumber: Data Penelitian, 2019

Hasil pengujian heteroskedastisitas pada Tabel 4 menunjukkan nilai probabilitas signifikansi masing-masing variabel bebas lebih dari 0,050 sehingga dapat disimpulkan bahwa model regresi dalam penelitian ini bebas dari heteroskedastisitas.

Hipotesis pertama menyatakan bahwa tekanan ketaatan berpengaruh negatif pada audit judgment yang dihasilkan oleh auditor di KAP se-Provinsi Bali. Pengujian hipotesis ini dilakukan dengan regresi linier sederhana. Hasil pengujian dapat dilihat pada Tabel 5 .

Tabel 5. Hasil Uji Regresi Linier Sederhana

\begin{tabular}{lccc}
\hline \multicolumn{1}{c}{ Model } & $\begin{array}{c}\text { Unstandardized } \\
\text { Coefficients } \\
B\end{array}$ & Sig & Hasil Uji \\
\hline (Constant) & 25,216 & 0,000 & Hipotesis \\
Tekanan Ketaatan (X1) & $-0,484$ & 0,000 & Diterima \\
Sig. F & & 0,000 & \\
Adjusted R Square & & 0,494 & \\
\hline
\end{tabular}

Sumber: Data Penelitian, 2019

Hasil penelitian menunjukkan nilai signifikansi $\mathrm{F}$ sebesar 0,000 lebih kecil dari $a=0,050$ yang berarti model yang digunakan dalam penelitian ini telah layak (fit). Hal ini menunjukkan bahwa tekanan ketaatan mampu memprediksi atau menjelaskan audit judgment yang dihasilkan auditor di KAP se-Provinsi Bali. 
Besarnya nilai Adjusted $R$ Square adalah 0,494. Hal tersebut menunjukkan bahwa variabilitas audit judgment dapat dijelaskan oleh komleksitas tugas sebesar 49 persen, sedangkan sisanya sebesar 51 persen dijelaskan oleh variabelvariabel lain di luar penelitian.

Dilihat dari beta unstandardized tekanan ketaatan bernilai negatif sebesar 0,484 dengan nilai signifikansi 0,000 lebih dari $a=0,05$ yang berarti bahwa secara langsung tekanan ketaatan berpengaruh negatif pada audit judgment. Berdasarkan hasil penelitian tersebut maka hipotesis pertama diterima.

Penelitian ini menguji pengaruh tekanan ketaatan pada audit judgment. Penelitian ini dilakukan dengan menggunakan responden auditor yang bekerja pada Kantor Akuntan Publik (KAP) se-Provinsi Bali. Hasil pengujian hipotesis pertama yang diuji dengan regresi linier sederhana menunjukkan tekanan ketaatan berpengaruh negatif pada audit judgment.

Teori atribusi mengarumentasikan bahwa perilaku seseorang ditentukan oleh kombinasi antara kekuatan internal dan eksternal. Perilaku yang disebabkan oleh kekuatan internal tersebut diyakini berasal dari dalam pribadi individu itu sendiri. Selain faktor internal, auditor juga menghadapi faktor eksternal yaitu tekanan ketaatan. Auditor menghadapi tekanan ketaatan dari klien, atasan, bahkan rekan kerja ketika melakukan audit judgment.

Hasil penelitian ini mendukung hasil penelitian yang telah dilakukan sebelumnya seperti Rosadi dan (Rosadi \& Waluyo, 2017) yang menyatakan bahwa tekanan ketaatan berpengaruh terhadap audit judgment para auditor. Tekanan ketaatan yang semakin besar menyebabkan auditor membuat audit judgment yang kurang tepat. Auditor harus mampu mengatasi tekanan yang diterima dari pihak lain dengan mampu menunjukkan integritas yang tinggi dan profesionalismenya (Pertiwi \& Budiartha, 2017). Oleh karena itu, auditor diharapkan bisa bekerja dengan profesional sesuai dengan aturan kode etik profesi.

Hipotesis kedua menyatakan bahwa religiusitas mampu memperlemah pegaruh tekanan ketaatan pada audit judgment. Pengujian hipotesis kedua dilakukan dengan menggunakan uji interaksi atau MRA. Hasil pengujian dapat dilihat pada Tabel 6 sebagai berikut.

\section{Tabel 6. Hasil Uji MRA}

\begin{tabular}{lccc}
\hline \multicolumn{1}{c}{ Model } & $\begin{array}{c}\text { Unstandardized } \\
\text { Coefficient } B\end{array}$ & Sig. & Hasil Uji \\
\hline (Constant) & 1,597 & 0,769 & \\
Tekanan Ketaatan (X1) & 0,169 & 0,422 & Hipotesis \\
Religiusitas (X2) & 0,316 & 0,000 & Diterima \\
Interaksi X1*X2 & $-0,008$ & 0,028 & \\
Sig. F & & 0,000 & \\
Adjusted R Square & & 0,660 & \\
\hline
\end{tabular}

Sumber: Data Penelitian, 2019

Berdasarkan hasil analisis uji MRA yang ditunjukkan pada tabel 6 dapat dilihat bahwa nilai signifikansi $\mathrm{F}$ sebesar 0,000 lebih kecil dari $a=0,05$ yang berarti bahwa model yang digunakan dalam penelitian ini telah layak (fit). Hal ini menunjukkan bahwa tekanan ketaatan dan religiusitas secara Bersama-sama 
mampu memprediksi atau menjelaskan audit judgment yang dihasilkan auditor di KAP se-Provinsi Bali.

Dari besarnya nilai Adjusted $R$ Square adalah 0,660. Hal tersebut menunjukkan bahwa variabilitas audit judgment dapat dijelaskan oleh tekanan ketaatan dan religiusitas sebesar $66 \%$ sedangkan sisanya sebesar $34 \%$ dijelaskan oleh variabel-variabel lain di luar model penelitian.

Dilihat dari nilai signifikansi interaksi kompleksitas tugas dan religiustas sebesar 0,028 lebih kecil dari $a=0,05$ menunjukkan bahwa religiusitas mampu memoderasi pengaruh tekanan ketaatan pada audit judgment. Beta Unstandardized interaksi tekanan ketaatan dan religiusitas yang bernilai $-0,008$ menunjukkan bahwa variabel pemoderasi religiusitas mampu memperlemah pengaruh tekanan ketaatan pada audit judgment, maka dari itu hipotesis kedua diterima.

Penelitia ini mencoba untuk menguji kemampuan religiusitas dalam memoderasi pengaruh tekanan ketaatan pada audit judgment. Hasil regresi MRA menunjukkan bahwa variabel pemoderasi religiusitas mampu memperlemah pengaruh tekanan ketaatan pada audit judgment, sehingga hasil penelitian mendukung hipotesis yang diajukan.

Hasil penelitian ini mendukung argumen yang dicetuskan oleh (Evanauli \& Nazaruddin, 2013) bahwa tingkat religiusitas seorang auditor mempengaruhi kecenderungan auditor untuk tidak melakukan perilaku disfungsional audit. Kekuasaan klien dan pemimpin menyebabkan auditor tidak independen lagi, karena auditor menjadi tertekan dalam menjalankan pekerjaanya. Klien atau pimpinan bisa saja menekan auditor untuk melanggar standar profesi auditor. Hal ini tentunya akan menimbulkan tekanan pada diri pemeriksa (Martini \& Pertama, 2019). Evanuli dan Nazaruddin (Evanauli \& Nazaruddin, 2013) juga menyebutkan dalam penelitiannya bahwa inndividu menjadikan agama sebagai landasan dalam kehidupannya, dan sadar akan adanya Tuhan. Oleh karena itu menghindari hal-hal yang menyimpang dari agama seperti melakukan kecurangan. Perilaku disfungsional tersebut dapat menyebabkan auditor berperilaku kurang etis dan profesional sehingga akan berdampak pada kualitas judgmentnya. Sikap religius diantisipasi dapat mempengaruhi pertimbangan etis akuntan (Hunt \& Vitell, 1993). Beberapa studi telah menunjukkan bahwa semakin tinggi tingkat religiusitas individu maka semakin tinggi pula kemungkinan individu berperilaku etis (Conroy \& Emerson, 2004).

\section{SIMPULAN}

Berdasarkan hasil analisis dan pembahasan maka dapat disimpulkan bahwa tekanan ketaatan berpengaruh negatif terhadap audit judgment. Hal tersebut menunjukkan bahwa semakin tinggi tekanan ketaatan yang dihadapi auditor maka kualitas audit judgment yang dihasilkan akan semakin rendah. Religiusitas mampu memoderasi pengaruh tekanan ketaatan pada audit judgment. Tingkat religiusitas seorang auditor mempengaruhi kecenderungan auditor untuk melakukan perilaku disfungsional audit yang kemungkinan terjadi ketika auditor mendapatkan tekanan ketaatan. Berdasarkan temuan penelitian ini Kantor Akuntan Publik hendaknya mempertimbangkan aspek religiusitas dalam sistem pengendalian mutu Kantor Akuntan Publik guna meningkatkan aspek 
perilaku etis auditor dan mengurangi kemungkinan auditor untuk berperilaku disfungsional dalam menjalankan tugasnya.

\section{REFERENSI}

Ajzen, F. M. (1980). Understanding Attitudes And Predicting Social Behavior. NJ: Prentice Hall.

Alteer, A. M., \& Taher, M. M. (2015). Religiosity and Ethical Decision Sensitivity in Auditing Profession. Journal of Economics and Bussiness Study, (1), 3-12.

Astriningrum, T. R. (2012). Pengaruh Gender, Kompleksitas Tugas, Tekanan Ketaatan, Dan Pengalaman Audit Terhadap Audit Judgment (Studi Kasus Pada Kantor Akuntan Publik di DKI Jakarta). Universitas Bina Nusantara.

Barnett, T., Bass, K., \& Brown, G. (1996). Religiosity, ethicalideology, and intentions to report a peer's wrongdoing. Journal of Business Ethics, 15(11), 1161-1174.

Bedard, J., \& Michelene, C. T. . (1993). Expertise in Auditing. Journal of Accounting Practice \& Theory, 12, 21-45.

Clary, E. G., \& Snyder, M. (1991). A functional analysis of altruism and prosocial behavior: The case of volunteerism. Review Ofpersonality and Social Psychology, 12, 119-148.

Conroy, S., \& Emerson, T. (2004). Business ethics and religion: Religiosity as a predictor of ethical awareness among students. Journal of Business Ethics, 50(4), 383-396.

Evanauli, R. P., \& Nazaruddin, I. (2013). Penerimaan Auditor Atas Dysfunctional Audit Behavior: Sebuah pendekatan Karakteristik Personal Auditor. UMY JurnalAkuntansi Dan Investasi, 14(2), 158-167.

Ghozali, I. (2004). AplikasiAnalisis Multivariate dengan Program SPSS. Semarang: Badan Penerbit Universitas Diponegoro.

Govindarajan, V. (1986). Impact Of Participation In The Budgetary Process On Management Attitudes And Performance: Universalistic And Contigency Perspectives. Decision Sciences, 496-516.

Hartanto, H. Y., \& Wjaya, I. (2001). Analisis Pengaruh Tekanan Ketaatan Terhadap Judgment Auditor. Jurnal Akuntansi Dan Manajemen.

Hogarth, R. M., \& Einhorn, H. J. (1992). Order Effects In Belief Updating: The Belief- Adjustment Model. Cognitive Psychology, 24(1), 1-55.

Hood, R. W., Greildan, A. L., \& Bromley, D. G. (2003). In Religion: Critical Approaches to Drawing Boundaries Between Sacred And Secular. Spirituality and Religion, 241-264.

Hunt, S. D., \& Vitell, S. J. (1993). The general theory of marketing ethics: A retrospective and revision. N. C. Smith \& J. A. Quelch (Eds.), Ethics in Marketing, 775-784.

Idris, S. F. (2012). Pengaruh Tekanan Ketaatan, Kompleksitas Tugas, Pengetahuan Dan Persepsi Etis Terhadap Audit Judgment (Studi Kasus Pada Perwakilan BPKP Provinsi DKI Jakarta). Universitas Diponegoro Semarang.

Jamilah, S., Fanani, Z., \& Chandrarin, G. (2007). Pengaruh Gender, Tekanan Ketaatan, Dan Kompleksitas Tugas Terhadap Audit Judgment. Simposium Nasional Akuntansi X.

Magdalena, M., Sofiani, O. L., \& Tjondro, E. (2014). Pengaruh Tekanan Ketaatan, 
Pengalaman Audit, Dan Audit Tenure terhadap Audit Judgement. Tax $\mathcal{E}$ Accounting Review, 4(1).

Martini, N. P. R., \& Pertama, I. G. A. W. (2019). Perilaku Disfungsional Auditor: Dampak Kompetensi Auditor, Sifat Machiavellian, Tekanan Waktu Dan Tekanan Ketaatan (Studi Kasus KAP di Bali). Wacana Ekonomi (Jurnal Ekonomi, Bisnis Dan Akuntansi), 18(1).

Murray, D. (1990). The Performance Effects of Participative Budgeting, an Interpretation of Intervening and Moderating Variables. Behavioral Research in Accounting, 2, 104-123.

Nazaruddin, I. (2011). Dampak Relijiusitas, Relativisme, Dan Idealisme Terhadap Penalaran Moral Dan Prilaku Manajemn Laba. Universitas Diponegoro.

Pertiwi, K. U. C., \& Budiartha, K. (2017). Pengaruh Tekanan Ketaatan, Independensi, Pengalaman Kerja, Locus Of Control Terhadap Audit Judgment di KAP BALI. E-Jurnal Akuntansi Universitas Udayana, 19(1), 712740 .

Praditaningrum, A. S. (2012). Analisis Faktor-Faktor Yang Berpengaruh Terhadap Audit Judgment (Studi Pada BPKP RI Perwakilan Provinsi Jawa Tengah). Universitas Pembangunan Nasional.

Puspitasari, N. E. (2014). Pengaruh Gender, Tekanan Ketaatan, Komplesitas Tugas, Pengetahuan Dan Persepsi Etis Terhadap Audit Judgment (Studi Empiris pada Kantor Akuntan Publik di Surakarta dan Yogyakarta). Universitas Muhammadiyah, Surakarta.

Rosadi, R. A., \& Waluyo, I. (2017). Pengaruh Gender, Tekanan Anggaran Waktu Dan Pengalaman Audit Terhadap Audit Judgment. Jurnal Nomial, VI(1).

Saifudin, A. (2001). Metode Penelitian Pendidikan. Yogyakarta: Pustaka Belajar. Sugiyono. (2013). Metode Penelitian Bisnis. Bandung: Alfabeta.

Wibowo, A., \& Rossieta, H. (2009). Faktor-Faktor Determinasi Kualitas Audit Suatu Studi Dengan Pendekatan Earning Surprise Benchmark. Simposium Nasional Akuntansi XII Palembang.

Wijayatri, A. (2010). Pengaruh Tekanan Ketaatan, Kompleksitas Tugas dan Keahlian Audit terhadap Audit Judgment (Studi Empiris pada Kantor Akuntan Publik di Surabaya). Universitas Pembangunan Nasional.

Worthington, E. L., Wade, N. G., Hight, T. L., McCullough, M. E., Berry, J. T., Ripley, J. S., ... O'Connnor, L. (2003). The Religious Commitment Inventory10: Development, Refinement, and Validation of a Brief Scale for Research and Counseling. Journal of Counseling Psychology, 50(1), 84-96. 